\title{
"PAPÉIS" DE GÊNERO, HOMOSSEXUALIDADE E ESCOLA: POSSÍVEIS DIÁLOGOS ENTRE EDUCAÇÃO E ESTUDOS DE GÊNERO
}

GENDER ROLE, HOMOSSEXUALITY AND SCHOOL:

POSSIBLE DIALOGUES BETWEEN EDUCATION AND GENDER STUDIES

\section{Diego de Medeiros Pereira' e Luiz Henrique Casett Horn²}

RECEBIDO EM: 10/06/2017 | APROVADO EM: 30/07/2017

DOI: $10.5902 / 2317175827623$

\section{RESUMO}

O presente texto trata de uma breve discussão sobre os papéis sociais atribuídos aos sujeitos a partir de seu sexo biológico e de como essa construção sociocultural define normas de conduta moral e comportamental - heteronorma - desqualificando sujeitos que a ela não se adequam. A partir dessa afirmação, apresenta-se a figura do "inadaptado", termo defendido por Mead (2009) e com o qual se relaciona a homossexualidade. A escola é defendida como espaço no qual as questões de gênero devam ser debatidas, respeitando a diversidade, e não apenas como reprodutora de valores construídos pela sociedade.

Palavras-chave: Gênero; Homossexualidade; Escola.

\footnotetext{
1 Professor Adjunto do Departamento de Artes Cênicas da Universidade Federal de Santa Maria. Doutor e Mestre em Teatro pelo Programa de Pós-Graduação em Teatro da Universidade do Estado de Santa Catarina. Licenciado em Educação Artística com habilitação em Artes Cênicas por essa Universidade. E-mail: diego.pereira@ufsm.br.

2 Advogado e Consultor Jurídico. Bacharel em Direito pela Universidade Federal de Santa Catarina. Pós-Graduando em Direito Público pela Universidade Estácio de Sá. E-mail: luiz.hrh@gmail.com
} 
"PAPÉIS" DE GÊNERO, HOMOSSEXUALIDADE E ESCOLA:

POSSÍVEIS DIÁLOGOS ENTRE EDUCAÇÃO E ESTUDOS DE GÊNERO

\begin{abstract}
This paper deals with a brief discussion about the social roles attributed to the subjects because of their biological sex and how this social and cultural conceiving defines norms of moral conduct and behavior - heteronormativity - disqualifying subjects that do not fit in it. From this statement, the figure of the "misfit", a term proposed by Mead (2009) which homosexuality is related. The school is framed as a space in which gender issues must be debated, respecting diversity, and not just as a reproducer of values built by society.
\end{abstract}

Keywords: Gender; Homossexuality; School.

\title{
1 Introdução
}

Refletir sobre os "papéis" de gênero atribuídos aos sujeitos pelas instituições que reafirmam as normas e condutas de uma determinada sociedade coloca-se como um desafio necessário à compreensão das diferentes construções sexuais existentes. No terreno da escola, essa reflexão se faz ainda mais urgente, tendo em vista que é um dos primeiros ambientes comunitários nos quais as crianças são inseridas e nos quais valores como o respeito à diversidade necessitam ser cultivados.

Parte-se de uma localização do gênero como categoria de análise subjetiva entrelaçada a outros fatores que influenciam na definição de homem e mulher, e das ações, condutas e comportamentos atribuídos a essas construções. A escola, como responsável pela "transmissão" de valores e saberes, configura-se, muitas vezes, como espaço de reafirmação de estereótipos de gênero, ao invés de desconstruir tais imposições socioculturais.

No que tange à construção das sexualidades, há a reprodução de um padrão sexual, entendido como heteronormativo, que, quando não cumprido, acarreta na exclusão e opressão de alguns sujeitos, os quais são entendidos, neste estudo, como "inadaptados", a partir da expressão defendida por Mead (2009).

Dessa forma, o presente texto tem intuito de, a partir das experiências de pesquisa e de vida de seus autores - professor e advogado homossexuais - traçar uma reflexão acerca das práticas educacionais e sociais que excluem a homossexualidade como uma manifestação de sexualidade possível de ser vivida.

\section{2 "Papéis" de Gênero e a Figura do Inadaptado (na Escola)}

O "gênero" deve ser entendido, da mesma maneira que a "classe social" e a "raça", como uma categoria de análise do sujeito. Dessa forma, ao se adentrar nos "estudos de gênero", de maneira geral, deve-se ficar atento ao fato de que há interseccionalidade entre gênero, raça e classe. Para fins didáticos, entretanto, far-se-á um recorte apenas na categoria gênero, para não fugir aos fins propostos pelo presente trabalho. 
O gênero foi construído como uma categoria que, inicialmente, atribuiu papéis sociais e culturais ao que se convencionou chamar de "homem" e "muIher", ou seja, socialmente se construíram obrigações diferentes para os corpos sexuados, a depender em qual categoria fosse o ser humano "destinado" a pertencer. Segundo Scott,

O gênero torna-se, antes, uma maneira de indicar "construções sociais" - a criação inteiramente social de ideias sobre os papéis adequados aos homens e às mulheres. É uma maneira de se referir às origens exclusivamente sociais das identidades subjetivas dos homens e das mulheres. O gênero é, segundo esta definição, uma categoria social imposta sobre um corpo sexuado (SCOTT, 1990, p. 07).

A autora afirma, desse modo, que a categoria gênero influencia as relações sociais, fundando-se sobre as diferenças sexuais, sendo um primeiro momento em que se estabelecem as relações de poder (SCOTT, 1990). Quer isso dizer que, a partir do momento em que se estabelecem diferenças sexuais, como, por exemplo, definindo-se a existência de um pênis ou uma vagina, dá-se início a diferentes relações de poder que permeiam a sociedade a partir dessa definição biológica.

A escola, como uma micro sociedade, ao mesmo tempo em que é composta por diferentes sujeitos/subjetividades, imprime-se como uma instituição que, de maneira geral, reproduz os modelos de homem e mulher. Secretarias de educação, diretores, professores, coordenadores pedagógicos e demais servidores que compõem, em conjunto com os estudantes e materiais didáticos, esse espaço educacional, tendem a ditar posturas esperadas para um sexo ou outro, reproduzir valores pessoais e estigmatizar aqueles que não se adequem a essas imposições.

A esses profissionais é necessária a compreensão de que a categoria gênero não se confunde com o sexo, haja vista que essa última está ligada, prioritariamente, à questão biológica, enquanto que a primeira tem um cunho eminentemente psicossocial. Nessa perspectiva, o gênero é intrínseco à construção subjetiva dos indivíduos, estando em um campo alheio, mas não completamente independente, ao sexo. Amâncio afirma que

[...] o género não é uma mera representação do estímulo sexo, nem um factor mediador entre o estímulo e a resposta, mas sim uma construção do sexo, que dá sentido à nossa identidade sexual e às dos outros, aos objetos e aos contextos sexuados, numa lógica simbólica que não deixa de sofrer influência da lógica sociológica da posição relativa dos indivíduos (AMÂNCIO, 2001, p. 16). 
"PAPÉIS" DE GÊNERO, HOMOSSEXUALIDADE E ESCOLA:

POSSÍVEIS DIÁLOGOS ENTRE EDUCAÇÃO E ESTUDOS DE GÊNERO

A partir disso, entende-se que os "papéis de gênero" são socialmente construídos, e, em razão disso, são mutáveis tanto no tempo quanto no espaço. Desse modo, uma mesma sociedade não atribui à mulher, por exemplo, os mesmos papéis que lhe atribuía há cinquenta anos e, da mesma forma, duas sociedades com culturas distintas não designam os mesmos papéis sociais às mulheres, ainda que se encontrem no mesmo lapso temporal.

Diante do fato de que os papéis sociais atribuídos pela categoria gênero são espacialmente e temporalmente modificáveis, não somente quando em relação a uma mesma categoria - por exemplo, mulher -, mas também são intercruzados - uma sociedade atribui a delicadeza à mulher, enquanto outra pode atribuí-la ao homem -, percebe-se que a biologia não influencia o modo como serão essas construções sociais realizadas. Sob essa perspectiva, Mead expõe que

\begin{abstract}
Comparando o modo como dramatizaram a diferença de sexo, é possível perceber melhor que elementos são construções sociais, originalmente irrelevantes aos fatos biológicos do gênero de sexo. Nossa própria sociedade usa muito essa trama. Atribui papéis diferentes aos dois sexos, cerca-os desde o nascimento com uma expectativa de comportamento diferente, representa o drama completo do namoro, casamento e paternidade conforme os tipos de comportamento aceitos como inatos e, portanto, apropriados a um ou a outro sexo. Sabemos vagamente que esses papéis mudaram mesmo dentro de nossa história (MEAD, 2009, p. 22-23).
\end{abstract}

Desse modo, portanto, quando a mãe e/ou o pai de um nascituro, por meio de um exame de ultrassom, descobre qual a genitália da criança, quase que automaticamente a generalidade dos pais e mães definem a cor das roupas que o infante irá vestir, quais os detalhes do berço do bebê, os brinquedos com que essa criança irá lidar no decorrer de sua infância, o nome dela, a maneira que ela deve se comportar, a forma de educar e até mesmo as possíveis profissões que irá exercer.

A escola é uma das grandes propagadoras dos comportamentos socialmente esperados de um homem e uma mulher, ao definir que os meninos jogam futebol enquanto as meninas, vôlei, ou que se aceite que os meninos sejam mais agressivos, enquanto às meninas seja imposto um comportamento dócil e "recatado". Muitas vezes, exige-se das meninas um amadurecimento precoce, assim que aparecem sinais da puberdade, enquanto aos meninos permite-se uma vivência mais prolongada da infância e mesmo um "desleixo" no período da adolescência.

Não somente em relação às crianças, mas também no que tange aos adultos essa imposição sociocultural recai: o modo de se portar, as roupas do dia-a-dia, o corte de cabelo, o cuidado pessoal (como fazer as unhas e se maquiar), a própria divisão dos trabalhos domésticos e não domésticos. Todo esse repertório de ações é socialmente construído para determinar qual a função do homem e qual a função da mulher em dada sociedade. 
Ao se atribuir as características de frágil, dócil e submissa às mulheres, enquanto que aos homens são outorgados os atributos de agressivo, forte e dominador, qualquer mulher ou homem que destoe da característica esperada pela categoria a qual pertença será visto como desviante da norma padrão, considerado não natural. Para comprovar que os atributos ligados ao feminino e ao masculino são construções sociais, Mead estudou o comportamento de homens e mulheres de três tribos nativas da Nova Guiné ${ }^{3}$ e chegou à conclusão de que

[...] quando se compreende que, enquanto os Arapesh padronizavam a personalidade tanto de homens como de mulheres num molde que, fora de nossa tendência tradicional, descreveríamos como maternal, feminino, não masculino, os Mundugumor chegaram ao extremo oposto e, novamente desprezando o sexo como base para o estabelecimento de diferenças de personalidade, padronizaram o comportamento de homens e mulheres como ativamente masculinos, viris e sem quaisquer das características suavizadoras e adoçantes que estamos acostumados a crer inalienavelmente femininas [...] (MEAD, 2009, p. 168).

Infere-se, por conseguinte, que os temperamentos feminino e masculino não estão ligados à questões biológicas, mas sim a questões de como as relações sociais se constroem em determinada comunidade. Quer dizer, o sexo não determina em absolutamente nada o modo de se portar ou agir de um indivíduo. Ratificando esse posicionamento, Mead reitera que

Se aquelas atitudes temperamentais que tradicionalmente reputamos femininas - tais como passividade, suscetibilidade e disposição de acalentar as crianças - podem tão facilmente ser erigidas como padrão masculino numa tribo, e na outra ser prescritas para a maioria das mulheres, assim como para a maioria dos homens, não nos resta mais a menor base para considerar tais aspectos de comportamento como ligados ao sexo (MEAD, 2009, p. 268).

Cabe, por fim, destacar que aqueles que não se adequam às normas sociais que balizam o gênero são considerados por Mead (2009) como "inadaptados". O inadaptado seria o indivíduo que foge às normas sociais de relações de gênero, por considerá-las absurdas, equivocadas ou por simplesmente não ser capaz de ou não querer se harmonizar com elas em razão de sua própria construção subjetiva, é considerado desviante da conduta normal e, muitas vezes, considerado antinatural, haja vista que há uma tendência de naturalizar a norma social imposta. Sob essa perspectiva, a sociedade (e novamente a escola tem grande responsabilidade nessa inclusão/exclusão) tenta controlar o comportamento sexual dos indivíduos, como bem evidencia Mead: 
"PAPÉIS" DE GÊNERO, HOMOSSEXUALIDADE E ESCOLA:

POSSÍVEIS DIÁLOGOS ENTRE EDUCAÇÃO E ESTUDOS DE GÊNERO

\begin{abstract}
A ameaça de que não irá comportar-se como membro de seu próprio sexo é usada para impor mil detalhes de rotina educacional e asseio, maneiras de sentar e descansar, ideias de esportividade e honestidade, padrões de expressão de emoções e uma multidão de outros pontos em que reconhecemos diferenças de sexo socialmente definidas, tais como limites de vaidade pessoal, interesse em roupas ou em acontecimentos atuais. [...] Toda vez que se toca no ponto da conformação do sexo, toda vez que o sexo da criança é invocado como motivo pelo qual deveria preferir calças a saias, bastões de beisebol a bonecas, murros a lágrimas, incute-se na mente da criança um medo de que, apesar da evidência anatômica contrária, ela pode realmente não pertencer ao seu próprio sexo (MEAD, 2009, p. 283).
\end{abstract}

A conformação do indivíduo às normas sociais, consequentemente, é muitas vezes embasada no medo de ser diferente dos demais e, por decorrência, ser excluído do convívio social. Essa imposição é tão perversa que faz com que crianças e adolescentes se adequem a tais normativas, ainda que isso signifique desconsiderar sua própria personalidade, muitas vezes ainda em construção.

Assim como as definições de papéis de gênero são construções sociais, não se estruturando na biologia - apesar das tentativas biologizantes -, a moral e as normas de conduta também são construídas a partir das relações societárias, tendo em conta que são mutáveis tanto no tempo quanto no espaço. Nessa linha de pensamento, expõe Foucault que

[...] no início do século XVII [...] Eram frouxos os códigos da grosseria, da obscenidade, da decência, se comparados com os do século XIX. Gestos diretos, discursos sem vergonha, transgressões visíveis, anatomias mostradas e facilmente misturadas, crianças astutas vagando, sem incômodo, sem escândalo, entre os risos dos adultos: os corpos "pavoneavam" (FOUCAULT, 2011, p. 09).

Percebe-se, portanto, que os códigos morais não são estáticos, mas desenvolveram-se ao longo dos séculos e que, nesse sentido, não caberia a escola reproduzir e impor normas conservadoras, machistas e lgbtfóbicas que diferenciam comportamentos em função da sexualidade. Faz-se necessário, em uma sociedade plural, compreender e fazer compreender as construções individuais, mesmo aquelas com as quais não se identifica, mas que pertencem a determinado grupo ou sujeito. Essa é uma postura que se espera de um professor comprometido com a construção de uma sociedade mais igualitária.

A figura do inadaptado, em vista disso, está intimamente ligada às questões da moralidade, devendo se esboçar, antes de se adentrar nos imbróglios da heteronormatividade, como a moral sexual ${ }^{4}$ sofreu transformações ao longo do tempo. Seguindo a linha de pensamento de Foucault, a moral deve ser entendida como

4 Ressalta-se que a expressão "sexualidade", tal qual se entende na atualidade, apenas surgiu no início do século XIX (FOUCAULT, 2012). 
[...] um conjunto de valores e regras de ações propostas aos indivíduos e aos grupos por intermédio de aparelhos prescritivos diversos, como podem ser a família, as instituições educativas, as Igrejas, etc. Acontece dessas regras e valores serem bem explicitamente formulados em uma doutrina coerente e em um ensinamento explícito. Mas acontece também delas serem transmitidas de maneira difusa e, longe de formarem um conjunto sistemático, constituírem um jogo complexo de elementos que se compensam, se corrigem, se anulam em certos pontos, permitindo, assim, compromissos e escapatórias. Com essas reservas pode-se chamar "código moral" esse conjunto prescritivo. Porém, por "moral" entende-se igualmente o comportamento real dos indivíduos em relação às regras e valores que lhes são propostos: designa-se, assim, a maneira pela qual eles se submetem mais ou menos completamente a um princípio de conduta [...] (FOUCAULT, 2012, p. 33).

A moral sexual, a partir do exposto, pode ser definida como os valores e as regras que estão atrelados ao comportamento sexual do indivíduo, sendo que existem diversas instituições que não apenas estão em constante observação para verificar se há adequação entre a conduta da pessoa e a norma a ser seguida, mas também que são polos de propagação dessa moral por meio de influências que exercem nas sociedades, tal como ocorre com as religiões, as escolas, a mídia, a família.

Como no Brasil toda criança a partir dos 04 anos de idade tem a obrigação de ser matriculada na escola e de nela permanecer até seus 17 anos, faz-se necessário rever os modos como as construções de valores a regras atrelados a uma moral sexual têm se dado, sobretudo o tratamento dado às crianças "desviantes" dos comportamentos a elas atribuídos por conta de seu sexo biológico.

\section{Heteronormatividade e Homofobia}

A partir da construção social dos papéis de gênero, concebe-se uma norma social para a sexualidade. Nessa perspectiva, a sociedade ocidental contemporânea adotou como norma sexual a heteronormatividade, isto é, o ser sexuado somente será considerado dentro da normalidade se for manifesta a heterossexualidade nele. E não somente isso, mas somente será considerado dentro dos padrões sociais aceitáveis se cumprir os papéis de gênero que a ele forem atribuídos.

Em razão disso, a heterossexualidade perpassa pelo campo da imposição, ou seja, a partir do momento em que se pretende definir a subjetividade dos indivíduos através da heteronorma, condicionando seus modos de se portar, suas atribuições dentro da sociedade - como empregos -, sua vestimenta e até mesmo a cor atribuída a seu gênero socialmente definido, subtrai-se do indivíduo a naturalidade de manifestação de sua sexualidade.

Profissionais da educação que trabalham com crianças mais novas, por exemplo, percebem que tanto meninas quanto meninos brincam com bone- 
"PAPÉIS" DE GÊNERO, HOMOSSEXUALIDADE E ESCOLA:

POSSÍVEIS DIÁLOGOS ENTRE EDUCAÇÃO E ESTUDOS DE GÊNERO

cas, com carro, de "casinha", divertem-se ao explorarem maquiagens, fantasias, experimentam diferentes cores nos seus desenhos, entre outras ações, quando ainda não sofreram a repressão por parte de algum adulto ou crianças nas quais os valores heteronormativos já estão introjetados. Ao observar-se o exposto acima, pode-se dialogar com Louro, a qual aduz que

[...] a heterossexualidade não é natural, e sim que é, como qualquer outra forma de sexualidade, construída e aprendida ao longo da vida. Apesar disso, se espera que todos sejam ou devam ser heterossexuais. A heterossexualidade assumiu um caráter compulsório nas sociedades ocidentais (LOURO, 2010, p. 145-146).

A autora afirma que a partir do momento que se impõe uma sexualidade aos indivíduos - e se faz isso constantemente através da família, da escola, da mídia -, essa sexualidade manifestada deixa de ser naturalmente vivida pelo sujeito. A "norma heterossexual" permeia a sociedade como um todo, estando imbricada em suas instituições, mas, principalmente, na escola, espaço no qual a criança é obrigada a estar.

Sabe-se que existe uma série de projetos pedagógicos e práticas educacionais que buscam desconstruir os estereótipos de gênero, mas são muito maiores as práticas sociais e culturais que tolhem a manifestação natural das sexualidades humanas para que apenas uma seja aceita ao ser manifestada: a heterossexual. Nesse sentido, Louro expõe que

Uma vez que se espera que todos sejam (ou devam ser) heterossexuais, segue-se que as instituições e os sistemas de saúde ou de educação, a justiça ou mesmo a mídia são construídos, basicamente, à imagem e semelhança desses sujeitos. Como todo processo normativo, a heteronormatividade é onipresente. Ela é, também, praticamente, invisível e, de certo modo, silenciosa (LOURO, 2010, p. 146).

Diante do fato que apenas a heterossexualidade é socialmente aceita, como se fosse a única sexualidade natural a se manifestar nos indivíduos, toda e qualquer exteriorização de sexualidades que desviem da norma imposta são coibidas e consideradas anormais e antinaturais. Um exemplo pode ser extraído de Felipe e Guizzo (2004):

O Júlio, de dois anos e meio, gostava muito de utilizar um vestido roxo que estava disponibilizado no "Canto da Fantasia". No entanto, isso provocava certa inquietação nas professoras. Uma delas, inclusive, passou a chamá-lo de "Julinha" já que, para ela, ele demonstrava "características homossexuais" (FELIPE e GUIZZO, 2013, p. 34). 
Desse modo, apesar de todo e qualquer corpo sexuado sofrer com a heteronormatividade, por ela restringir a liberdade sexual dos indivíduos, é a manifestação da homossexualidade uma das que mais causa sofrimento às pessoas. A restrição à essa particular manifestação da sexualidade está fortemente respaldada por todo o sistema social: na saúde, campo em que homossexuais até o presente momento não podem doar sangue ${ }^{5}$, na religião - considerando a homossexualidade como pecado -, na educação - como no caso acima, em que o fato de um menino brincar com um vestido gerou uma atitude homofóbica por parte da professora - e, até pouco tempo, no próprio sistema jurídico ${ }^{6}$.

As restrições sexuais, entretanto, advêm da sociedade, e não dos sistemas em si, pois, ainda que esses sistemas sejam compostos por manifestações socioculturais, eles não são intrinsecamente restritivos. Esse fato se evidencia, por exemplo, quando mesmo numa sociedade extremamente homofóbica, como a brasileira, admite-se, juridicamente, o casamento civil entre homossexuais. Nesse sentido, corrobora Lopes ao afirmar que

[...] é evidente que há uma restrição forte ao exercício da liberdade sexual para determinados grupos, particularmente aos homossexuais. Essa restrição procede de o sistema jurídico ser interpretado com critérios morais que não provêm do próprio sistema, mas Ihe são enxertados pela opinião pública, uma opinião de massa em geral acrítica e sobretudo antiliberal, opinião que não aceita a autonomia dos sujeitos (LOPES, 2007, p. 67).

Nessa ótica, as estruturas sociais, reproduzindo a heteronormatividade, provocam a homofobia ${ }^{7}$. A reprodução da norma heterossexual se dá através do discurso da existência de papéis de gênero, definindo-se as atribuições dos indivíduos na sociedade a partir de sua classificação binária homem/mulher. Por sua vez, a homofobia é fruto dessa mesma classificação binária, entretanto, a partir da lógica homossexual/heterossexual. Nas palavras de Rios:

\footnotetext{
5 Conforme art. 64, IV, da Portaria 158, de 04 de fevereiro de 2016, expedida pelo Ministro de Estado da Saúde, segundo a qual homens que tiveram relações sexuais com outros homens não poderão doar sangue pelo prazo de 12 meses. Ressalte-se que está sendo questionada a constitucionalidade dessa portaria no Supremo Tribunal Federal por meio da Ação Direta de Inconstitucionalidade 5.543, com parecer do Procurador-Geral da República no sentido de que a referida portaria viola a Constituição, por ser discriminatória.

6 Até maio de 2011 os homossexuais não podiam casar e nem constituir união estável, sendo consideradas "inexistentes" as relações de afeto e compartilhamento da vida entre um casal homossexual. A partir da decisão da Ação Direta de Inconstitucionalidade 4.277 e da Arguição de Descumprimento de Preceito Fundamental 132, o Supremo Tribunal Federal decidiu, por unanimidade, que os direitos das uniões estáveis de pessoas de sexos diferentes são extensíveis às uniões de pessoas do mesmo sexo. Por sua vez, o Conselho Nacional de Justiça editou, em maio de 2013 a Resolução n 175, a qual estabeleceu o direito de

7 realizar casamento entre homossexuais. mossexuais. Para Rios, "Preconceito e discriminação são termos correlatos, que, apesar de designarem fenômenos diversos, são por vezes utilizados de modo intercambiado. [...] Por preconceito, designam-se as percepções mentais negativas em face dos indivíduos e de grupos socialmente inferiorizados, bem como as representações sociais conectadas a tais percepcões. Já o termo discriminação designa a materialização, no plano concreto, das relações sociais, de atitudes arbitrárias, comissivas ou omissivas, relacionadas ao preconceito, que produzem violação de direitos dos indivíduos e dos grupos" (RIOS, 2007, p. 112-113). Ou seja, enquanto preconceito permanece no plano subjetivo, a discriminação é a materiálização desse preconceito através de ações e omissões.
} 
"PAPÉIS" DE GÊNERO, HOMOSSEXUALIDADE E ESCOLA:

POSSÍVEIS DIÁLOGOS ENTRE EDUCAÇÃO E ESTUDOS DE GÊNERO

A relação umbilical entre sexismo e homofobia é um elemento importantíssimo para perceber a homofobia como derivação do heterossexismo. De fato, a literatura dedicada à homossexualidade dialoga constantemente com a noção de gênero. O binarismo classificatório, entre masculino e feminino, analisado nos estudos de gênero, de novo se apresenta no âmbito da sexualidade, agora através do par heterossexualidade/homossexualidade (RIOS, 2007, p. 122).

Desse modo, a homossexualidade confronta a heteronorma imposta e, em razão disso, questiona esse binarismo homem/mulher e, consequentemente, põe em xeque os papéis de gênero definidos socialmente. Não se pode esquecer, também, que a transexualidade, assim como a homossexualidade, enfrenta diretamente a heteronorma. Desta feita, o modo pelo qual o sistema busca manter e eliminar essas ameaças é a homofobia e a transfobia.

$\mathrm{Na}$ escola, a manutenção da heteronorma não se dá de modo diferente. Professores e estudantes não hesitam em vigiar comportamentos e apontar "desvios" da norma: "esse brinquedo é de menina", "esse cabelo curto é de menino", "menino não deve mexer muito as mãos pra falar", "menina não senta de perna aberta", "menino não chora", "isso é coisa de mulherzinha", "que viadagem", "correr é coisa de menino", entre uma infinitude de exemplos.

Ainda que muitos profissionais da educação tenham postura adversa às expressões citadas acima, pouco se faz no sentido de ampliar as discussões e trazer esses temas para as práticas pedagógicas. Britzman (apud Dinis, 2011) traz uma contribuição interessante nesse sentido:

[...] existe o medo de que a mera menção da homossexualidade vá encorajar práticas homossexuais e vá fazer com que os/ as jovens se juntem às comunidades gays e lésbicas. A ideia é que as informações e as pessoas que as transmitem agem com a finalidade de "recrutar" jovens inocentes. [...] Também faz parte desse complexo mito a ansiedade de que qualquer pessoa que ofereça representações gays e lésbicas em termos simpáticos será provavelmente acusada ou de ser gay ou de promover uma sexualidade fora da lei. Em ambos os casos, o conhecimento e as pessoas são considerados perigosos, predatórios e contagiosos. (BRITZMAN apud DINIS, 2011, p. 43).

A homofobia e a transfobia, como espécies de preconceito, não somente são permitidas, mas também as discriminações contra homossexuais e transexuais não são, de um modo geral, obstadas pela escola. Enquanto o racismo e o sexismo, por exemplo, são, ainda que insuficientemente, rechaçados - em regra, atitudes racistas e machistas causam olhares de desconforto, embora seja estrutural a existência de tais discriminações em nossa sociedade -, a homofobia e a transfobia dificilmente têm algum opositor e são raramente reprovadas nos espaços públicos e privados, pois a homossexualidade e a transexualidade confrontam, diretamente e mais incisivamente, a estrutura social do gênero, ameaçando-a. Para Rios, 
[...] se hoje são inadmissíveis as referências discriminatórias a negros, judeus e mulheres, ainda são toleradas, ou ao menos sobrelevadas, as manifestações homofóbicas. A persistência da homofobia ocorre, dentre outros fatores, porque a homossexualidade tende a afrontar de modo mais radical e incômodo as instituições e dinâmicas basilares na vida em sociedade (RIOS, 2007, p. 125-126). ${ }^{8}$

Desse modo, a despeito de se ter machismo e racismo estruturais na sociedade brasileira, a também estrutural homofobia - tal qual a transfobia - é um dos únicos preconceitos em que é admitida a discriminação sem que haja qualquer política pública de inclusão ou de coibição de atitudes homofóbicas e transfóbicas, seja por parte de indivíduos, seja por parte do Estado.

Uma iniciativa de combate à violência e discriminação contra LGBT foi o lançamento, em 2004, pelo Governo Federal, do Programa "Brasil sem Homofobia". Dentre as propostas para a Educação estava a produção de materiais educativos específicos para discutir questões como orientação sexual e homofobia. Em 2011, foram elaborados os materiais que compunham o "Escola sem Homofobia", que seria distribuído às escolas. Após pressão de setores conservadores da sociedade e do Congresso Nacional, entretanto, a distribuição foi vetada pelo governo. Esse fato apenas reforça o desejo, por parte de diversos agentes sociais, de manterem a heteronorma.

A heteronormatividade, portanto, cria a inadaptabilidade dos indivíduos que não se enquadram no padrão social imposto. A homofobia, por sua vez, viola os direitos do sujeito inadaptado homossexual, pois não somente coíbe seus desejos, atitudes e paixões, mas também cerceia o pleno desenvolvimento de sua personalidade ao não permitir que a pessoa seja aquilo que subjetivamente se constrói. Conforme Rios,

[...] a homofobia viola de modo intenso e permanente uma série de direitos básicos, reconhecidos tanto pelo direito internacional dos direitos humanos, quanto pelo direito constitucional. Ao lesionar uma gama tão ampla de bens jurídicos, a homofobia manifesta-se por meio de duas formas de violência: a física e a não física (RIOS, 2007, p. 129). ${ }^{9}$

\footnotetext{
$8 \quad$ Por esse viés, pode se afirmar que o Estado brasileiro busca tornar a sociedade mais igualitária quando cria leis de proteção às minorias. Nesse sentido, podem ser apontadas a Lei 7.716/89, que institui a criminalização do preconceito de raça ou de cor; a Lei 9.504/97, com redação dada pela Lei 12.034/09, segundo a qual o preenchimento de candidaturas em eleições políticas deverá ser de no mínimo 30\% e no máximo 70\% para cada sexo (cotas para mulheres nas eleições); a Lei 11.340/06 (Lei Maria da Penha), que cria mecanismo para coibir a violência doméstica contra a mulher; a Lei 12.990/14, que institui cotas para negros nos concursos públicos da União e suas autarquias, fundações, empresas públicas e sociedades de economia mista; a Lei 13.104/2015, que prevê o feminicídio como crime hediondo; os incisos II e XLII do art. $5^{\circ}$ da Constituição Federal, que preveem respectivamente que homens e mulheres são iguais em direitos e obrigações e que o racismo é crime inafiançável e imprescritível.

9 São exemplos de direitos lesionados pela homofobia: o bem-estar, a moralidade do indivíduo, a honra subjetiva, o pleno desenvolvimento de sua subjetividade - em suma, os direitos da personalidade de um modo geral -, o direito à educação, pois muitos homossexuais e transexuais abandonam os estudos por conta de forte preconceito que sofrem tanto de colegas quanto de professores, fazendo com que tenham menor nível de instrução formal; o direito ao trabalho, uma vez que homossexuais, em especial os afeminados, são massivamente discriminados pela maioria dos empregadores e de seus colegas de trabalho; o direito à integridade física - o simples andar de mãos dadas na rua com o(a) parceiro(a) é uma afronta à "moral e bons costumes". Até 2011 também era negado aos homossexuais o direito de ter reconhecido pelo Estado e pela sociedade a sua constituição familiar.
} 
"PAPÉIS" DE GÊNERO, HOMOSSEXUALIDADE E ESCOLA:

POSSÍVEIS DIÁLOGOS ENTRE EDUCAÇÃO E ESTUDOS DE GÊNERO

A homofobia, dessa maneira, não necessariamente é manifestada através da agressão física, mas também pode se materializar através de uma agressão verbal ou, até mesmo, estar atrelada à uma ação ou omissão que não agrida o indivíduo em sua esfera física, mas é tão violento quanto a agressão psíquica. Sobre essa questão, Dinis traz importante contribuição:

[...] o bullying homofóbico tem resultado na evasão escolar de estudantes que expressam identidades sexuais e de gênero diferentes da norma heterossexual, e mesmo nas tentativas de suicídio de adolescentes em conflito com sua identidade sexual e de gênero, devido aos preconceitos e a discriminação sofrida no espaço escolar. Uma das principais vítimas no processo de evasão escolar também são as adolescentes travestis e as (os) adolescentes transexuais que dificilmente conseguem terminar seus estudos, sendo forçadas (os) a abandonar a escola, já que diferentemente de adolescentes gays e lésbicas, têm mais dificuldade em esconder sua diferença, tornando-se as vítimas mais visíveis dessa violência escolar. (DINIS, 2011, p. 43).

Essa prática é realizada tanto por colegas quanto por professores. Exemplificativamente, um professor, ao se utilizar da suposta homossexualidade de dois estudantes que estão muito "grudados" e conversando para que cessem a conversa, age de forma extremamente violenta e homofóbica, pois além de expô-los para a classe, sua atitude reforça que a homossexualidade é algo que não deve ser praticada, sendo inclusive motivo de risadas. Argumenta Rios que

[...] a qualificação de um ato como homofóbico não depende da intencionalidade do ato ou da situação ocasionada da lesão aos direitos humanos e liberdades fundamentais afetados. Deste modo, há discriminação homofóbica sempre que, de modo proposital ou não, houver tal espécie de lesão a direitos, decorrente da concretização de preconceitos diante de estilos de ser e de viver divorciados do heterossexismo (RIOS, 2007, p. 130-131).

Diante disso, para que uma atitude seja homofóbica, não necessariamente ela precisa ser executa com a intenção de discriminação. O simples reforçar da heteronorma, seja através de uma ação, falada ou não, ou uma omissão diante de casos de homofobia que se apresentam, é compactuar com o preconceito contra homossexuais e cercear direitos da personalidade dessas pessoas, inclusive inibindo o integral desenvolvimento de suas subjetividades.

Para um país que ocupa o $5^{\circ}$ lugar no ranking mundial de feminicídio ${ }^{10}$ (4,8 assassinatos a cada 100 mil mulheres), com 343 LGBTT (lésbicas, gays, bissexuais, transexuais e travestis) assassinados no ano de $2016^{11}$ - o que coloca o Brasil como "campeão" de crimes contra minorias sexuais - vê-se que há muito o que se fazer em termos de educação para a diversidade e igualdade de gênero.

$10 \quad$ Dados do site www.compromissoeatitude.org.br

11 Dados do site www.homofobiamata.wordpress.com 


\section{Algumas Considerações}

As discussões levantadas ao longo do texto buscaram expressar uma visão crítica que compreende o gênero como categoria de análise do sujeito, a qual, a partir de uma construção sociocultural dos papéis sociais adequados aos sexos, impõe funções que não são naturais, mas naturalizadas. Desse modo, o gênero não deveria ser confundido com o sexo biológico, uma vez que o primeiro se caracteriza, essencialmente, por ser uma categoria psicossocial, enquanto que o segundo liga-se, primariamente, à biologia.

A partir dessa perspectiva, tratou-se da figura do "inadaptado", aquele que, não se adequando à norma imposta, sofre opressão e exclusão de seu grupo social. Essa inadequação, no âmbito dos Estudos de Gênero, está atrelada ao fato desse sujeito fugir aos padrões impostos pela heteronormatividade. Levando-se em consideração que a heteronorma é a padronização de uma sexualidade e que a escolha de diferentes manifestações (vestimentas, cores, comportamentos, etc.) deveriam ser derivações dessa padronização, o inadaptado caracteriza-se por manifestar uma sexualidade e escolhas não condizentes com aquelas esperadas.

No âmbito das práticas educacionais, argumenta-se acerca dos modos como os sujeitos que compõem o espaço da escola, em geral, reafirmam as normas sociais entendidas como um padrão. Enquanto outros temas sociais emergentes são discutidos na escola, a homofobia e demais atitudes contra minorias sexuais são silenciadas, ainda que em muitas escolas os inadaptados estejam presentes, escondidos ou não, sofrendo opressões e sua subjetividade violada pelo controle de suas ações.

Nesse contexto, considera-se fundamental que os professores, responsáveis pelos sujeitos em processo de formação, coloquem-se como mediadores de práticas que promovam o respeito à diversidade e a compreensão das diferentes construções sexuais. Sabe-se que uma mudança de postura é algo que necessita de investimento (de tempo, recursos materiais e financeiros) e formação complementar constante, pois dado que a cultura e a sociedade são dinâmicas, os saberes não devem ser cristalizados.

Por fim, em um Estado que se queira igualitário e livre, cabe aos profissionais da educação terem a dimensão de que suas crenças pessoais não podem estar acima das necessidades e particularidades das construções subjetivas dos indivíduos. 
"PAPÉIS" DE GÊNERO, HOMOSSEXUALIDADE E ESCOLA:

POSSÍVEIS DIÁLOGOS ENTRE EDUCAÇÃO E ESTUDOS DE GÊNERO

\section{Referências}

AMÂNCIO, Lígia. O Gênero na Psicologia: uma história de desencontros e rupturas. Revista Psicologia. Lisboa: Associação Portuguesa de Psicologia, 2001, v. XV, n. 1, p. 9-26.

DINIS, Nilson Fernandes. Homofobia e educação: quando a omissão também é signo de violência. Educar em Revista. Curitiba: Editora UFPR, 2011, n. 39, p. 39-50.

FELIPE, Jane; GUIZZO, Bianca Salazar. Entre batons, esmaltes e fantasia. In: MEYER, Dagmar; SOARES, Rosângela (orgs.). Corpo, Gênero e Sexualidade. Porto Alegre: Mediação, 2013, p. 31-40.

FOUCAULT, Michel. História da Sexualidade I: a vontade de saber. São Paulo: Editora Graal, 2011.

História da Sexualidade II: o uso dos prazeres. São Paulo: Editora Graal, 2012.

LOPES, José Reinaldo de Lima. Liberdade e Direitos Sexuais - o problema a partir da moral moderna. In: RIOS, Roger Raupp (org.). Em Defesa dos Direitos Sexuais. Porto Alegre: Editora Livraria do Advogado, 2007, p. 4172.

LOURO, Guacira Lopes. Sexualidades Minoritárias e Educação: novas políticas?. In: POCAHY, Fernando (org.). Políticas de Enfrentamento ao Heterossexismo: corpo e prazer. Porto Alegre: Edição NUANCES, 2010, p. 143-150.

MACHADO, Lia Zanotta. Gênero, um novo paradigma?. Cadernos Pagu, Campinas: Universidade Estadual de Campinas, 1998, v. 11, p. 107-125.

MEAD, Margaret. Sexo e Temperamento. São Paulo: Editora Perspectiva, 4ª Edição, 2009.

RIOS, Roger Raupp. O Conceito de Homofobia na Perspectiva dos Direitos Humanos e no Contexto dos Estudos sobre Preconceito e Discriminação. In: (org.). Em Defesa dos Direitos Sexuais. Porto Alegre: Editora Livraria do Advogado, 2007, p. 111-139.

SCOTT, Joan. Gênero: uma categoria útil de análise histórica. Revista Educação e Realidade. Porto Alegre: Universidade Federal do Rio Grande do Sul, 1990, v. 16, n. 2, p. 05-22. 